altitudes of 1,500 and 3,000 meters $(4,000$ and $8,000 \mathrm{ft})$. Ventilators were tested against models simulating a normal lung, a low compliance (ARDS) lung and a high-resistance (asthma) lung, with various $\mathrm{FiO}_{2}$. The volumes delivered were measured with dedicated instrument of the French Air Force physiological laboratory.

Results:

\begin{tabular}{|c|c|c|c|}
\hline & Normal Lung & Asthma & ARDS \\
\hline $\begin{array}{c}\text { LTV 1000: \% maxi- } \\
\text { mum variation V } \\
\text { delivered } / N_{\mathrm{t}} \text { set }\end{array}$ & +16 & +18 & -16 \\
\hline $\begin{array}{c}\text { T BIRD VSO2: } \\
\% \text { maximum } \\
\text { variation } V \\
\text { delivered } / N_{\mathrm{t}} \text { set }\end{array}$ & -17 & -18 & -22 \\
\hline
\end{tabular}

Conclusions: Both ventilators performed well. In hypo-barometric conditions, the LTV1000 showed mostly a moderate increase in volume delivered for normal lung and asthma and moderate decrease and increase for ARDS, whereas the TBIRD VSO2 showed a moderate decrease in all cases (more marked with $\mathrm{FiO}_{2}=21 \%$ ).

Keywords: air evacuation; altitude; ventilator

Prebosp Disast Med 2010;25(5):s89-s90

A Pilot Study of Performance of LTV1000 and TbirdVSO2 Ventilators at Simulated Altitude: Study of Fraction of Inspired Oxygen

Jean Pierre Tourtier; Thomas Leclerc; Borne

Military Hospital Val de Grâce, Paris, France

Introduction: The performance of two ventillators built with an advanced turbine delivery system (LTV1000 and TbirdVSO ${ }_{2}$ ) was studied. The ventilators' abilities to deliver a set fraction of inspired oxygen $\left(\mathrm{FiO}_{2}\right)$ in the face of cabin altitude change and compliance and resistance variation were compared.

Methods: A decompression chamber was used to simulate the hypo-barometric environment from 1,500 to 3,000 meters $(4,000$ to $8,000 \mathrm{ft})$. A model of normal lung was used. Ventilators were tested with $\mathrm{V}_{\mathrm{t}}=700 \mathrm{ml}$ and various $\mathrm{FiO}_{2}$ set $(21 \%, 50 \%, 90 \%)$. Each $\mathrm{FiO}_{2}$ set was noted, the effective $\mathrm{FiO}_{2}$ assessed by the ventilators (paramagnetic analysis) and the $\mathrm{FiO}_{2}$ delivered (dedicated instrument of the French physiological laboratory of aviation) was measured.

Results: The maximum variation of $\mathrm{FiO}_{2}$ really delivered compared to $\mathrm{FiO}_{2}$ set and $\mathrm{FiO}_{2}$ assessed is shown in the Table.

\begin{tabular}{|c|c|c|c|c|}
\hline Ventilator & $\begin{array}{c}\text { LTV } \\
\mathbf{1 0 0 0}\end{array}$ & $\begin{array}{c}\text { LTV } \\
\mathbf{1 0 0 0}\end{array}$ & $\begin{array}{c}\text { T BIRD } \\
\text { VSO2 }\end{array}$ & $\begin{array}{c}\text { T BIRD } \\
\text { VSO2 }\end{array}$ \\
\hline FiO2 set (\%) & 50 & 90 & 50 & 90 \\
\hline $\begin{array}{c}\text { \% variation } \mathrm{FiO} 2 \\
\text { delivered/set }\end{array}$ & -3 & +10 & +20 & +10 \\
\hline $\begin{array}{c}\text { \% variation } \mathrm{FiO} 2 \\
\text { delivered/ } \\
\text { assessed }\end{array}$ & +28 & +30 & +29 & +14 \\
\hline
\end{tabular}

Conclusions: Both ventilators showed a moderate variation between $\mathrm{FiO}_{2}$ set and delivered. On the other hand, variations between $\mathrm{FiO}_{2}$ delivered and assessed are high, suggesting the inefficiency of ventilators hypo-barometric conditions.

Keywords: air-evacuation; altitude; ventilator

Prehosp Disast Med 2010;25(5):s90

Medical Air Transportation with Tbird Ventilator: Cabin Altitude Must be Input!

Jean Pierre Tourtier; Thomas Leclerc; Borne

Military Hospital Val de Grâce, Paris, France

Introduction: Mechanical ventilators suffer from variations in the environmental pressure. For a Tbird ventilator, the cabin altitude value should be input manually, which might be tedious. The ability of the Tbird VS02 to deliver a set tidal volume at high altitude was assessed in two cases: with and without the input of cabin altitude.

Methods: A decompression chamber was used to mimic the hypo-barometric environment at a range of cabin simulated altitudes of 1,500 and 3,000 meters $(4,000$ and $8,000 \mathrm{ft}$ ). A model of a normal lung was used. The ventilator was tested with $\mathrm{V}_{\mathrm{t}}$ set $=400 \mathrm{ml}$ and various $\mathrm{FiO}_{2}(21 \%$, $50 \%, 90 \%$ ), with and without inputting cabin altitude. The volume delivered was measured using the dedicated instrument of the French Physiological Laboratory of Aviation and Space Medicine of the Air Force.

Results:

\begin{tabular}{|l|c|c|}
\hline & $1,500 \mathrm{~m}$ & $3,000 \mathrm{~m}$ \\
\hline$V_{t}$ set $(\mathrm{ml})$ & 400 & 400 \\
\hline $\begin{array}{l}\text { Volume delivered without input of } \\
\text { cabin altitude }\end{array}$ & $280 \pm 5$ & $125 \pm 10$ \\
\hline $\begin{array}{l}\text { Volume delivered with input of cabin } \\
\text { altitude }\end{array}$ & $385 \pm 5$ & $350 \pm 10$ \\
\hline \multicolumn{1}{|c|}{ Tourtier @ 2010 Prehospital and Disaster Medicine } \\
\hline
\end{tabular}

Conclusions: Performance of the Tbird $\mathrm{VSO}_{2}$ are reduced dramatically regarding $V_{t}$ if the value of cabin altitude is not input manually. Concomitantly to the development of highly specialized machines, there is the need to train personnel to optimize the performance of the ventilators.

Keywords: air-evacuation; altitude; ventilator

Prehosp Disast Med 2010;25(5):s90

\section{An Intensive Care Unit Taking Off?}

Jean Pierre Tourtier; Thomas Leclerc; Borne

Military Hospital Val de Grâce, Paris, France

Introduction: Aeromedical evacuation (MEDEVAC) is a dimensioning component of French Armed Forces foreign deployment. Considering the technical limitations of the previous collective MEDEVAC system (conversion of an Airbus A 310), the Ministry of Defense asked for a new one, designed for MEDEVAC of multiple critically injured patients.

Methods: A non-dedicated vector among existing French Air Force aircraft with cargo capacity, high range, and permanent availability was selected. A platform meeting medical and aeronautical standards was created, based on a combination of specifically designed, modifiable modules. 
Results: Eleven C135FR have been modified to accommodate the medical solution. The technical platform includes patient care modules (intensive care modules accommodating one mechanically ventilated patient; light care modifiable modules) and logistical modules (two racks, one preparation table, one centralized monitoring area). The medical team includes two anesthesiologists, three anesthesiology nurses, two emergency physicians, two nurses, two MEDEVAC nurses, and one medical specialist or liaison officer.

Conclusions: The MORPHEE system and its successful operational missions emphasize the versatility and efficiency of a solution based on mission-tailored "plug and play" modules easily and quickly installable aboard a non-dedicated aircraft.

Keywords: aero-evacuation; intensive care unit; military

Prehosp Disast Med 2010;25(5):s90-s91

"Doctor on Board": What is the Optimal Skill-Mix in Military Helicopter CASEVAC?

Douglas Bowley, ${ }^{1}$ Stuart Mercer, ${ }^{2}$ Gora Pathak, ${ }^{2}$

Jason Schrager,; Mike Kazel, ${ }^{2}$ Steve Bree ${ }^{2}$

1. Royal Centre for Defence Medicine, Birmingham, UK

2. Joint Medical Force Hospital, Bastion, Afghanistan

Introduction: Military prehospital times may be extended due to geographical or operational issues. The skill-mix of the prehospital team may vary. The aim of this study was to quantify the contribution of a physician to military prehospital care. Methods: Joint Force Medical Command Afghanistan Medical Emergency Response Team (MERT) missions were entered into a prospective log. Patient nationality, mechanism of injury, and whether the doctor was required to perform a medical intervention during the mission were recorded.

Results: A total of 324 recent MERT missions retrieved 429 patients. The median number of patients was 1 (range $1-13$ ). Of the troops, $56 \%$ were local nationals and $44 \%$ were coalition troops. Twenty-two percent were T1, 52\% were $\mathrm{T} 2,21.5 \%$ were $\mathrm{T} 3$, and $4 \%$ were dead. A total of $48 \%$ patients had blast injuries, $25 \%$ had gunshot wound/s (GSWs), six patients had blast and GSWs. A total of 41 patients (9.5\%) were medical, $23(5 \%)$ received injuries in road traffic collisions, and 42 patients had other diagnoses. Median time from take-off to delivery of the casualty was 44 minutes (range 10-183 minutes). A doctor flew on 88\% missions; the doctor was thought unnecessary in $77 \%$. Of the missions where a doctor was useful, the commonest intervention was rapid sequence induction (45\%), other interventions included provision of analgesia, sedation or blood products, chest drain or thoracostomy and pronouncing life extinct.

Conclusions: The MERT is a high-value asset that makes an important contribution to patient care. A relatively small proportion of missions require interventions beyond the capability of well-trained military paramedics.

Keywords: helicopter; military; physician; prehospital

Prehosp Disast Med 2010;25(5):s91
2008 Air Base 4 Clinic "Tenente Coronel Médico Viriato Garrett" Aerial Evacuations/Search and Rescue and in Flight Emergency Response

Lt. Ana Catarina Lagos, $P b D,{ }^{1}$ Lt. Ingrid Rosário, $P b D ; 1$ Sérgio Medina do Rosário, $P h D,{ }^{2}$

LtCol. Miguel Santos, $P h D^{1}$

1. Porruguese Air Force

2. USF Villa Longa, Portugal

Introduction: Air Base 4 clinic, a NATO "role 1" health unit, "Tenente Coronel Médico Viriato Garrett" scrambles medical teams for patients or injured people in need of air-medical evacuation, search-and-rescue, and/or in-flight emergencies.

Objective: The objective of this study was to characterize patients, diagnosis, and drug therapy involved in air-medical evacuations/search-and-rescue and in-flight emergencies in 2008.

Methods: This was an objective, cross-sectional, and descriptive study.

Results: Twenty passengers were evaluated following 19 in-flight emergencies (interruptions in commercial airliners). There was a predominance of males and acute cardiovascular pathology was most common. There were 13 patient air-medical evacuations from ships, with traumatic injuries and gastroenterology issues prevailing (analgesics and antiemetics were most widely administered). Eight search-and-rescue missions were accomplished, but in only one situation was a medical intervention needed to assist seven crew members with $1^{\text {st }}$ degree burns, who were hoisted from a fishing vessel, then flown to a hospital.

Conclusions: Due to its central geostrategic location at the crossroads of transatlantic shipping and air lanes, Lajes Air Base plays an essential role in the stabilization and transportation of ill persons from vessels and also provide medical care to emergencies developing in commercial and military flights.

Keywords: air evacuation; in-flight emergencies; military medicine; search and rescue

Prebosp Disast Med 2010;25(5):s91

\section{Role of Local-Regional Analgesia during Medical Evacuation \\ Marzio G. Mezzetti, $M D, P h D$; Gratiliano Gai, $M D$ \\ Ministry of Welfare, Department of Health, Italy}

Today, local-regional analgesia represents a simple and effective alternative to deep sedation or general anesthesia during medical transport of patients with severe traumatic injuries. Particularly for patients with fractures and/or penetrating injuries of the extremities, shoulder and/or thorax, local-regional analgesia could be performed using safe and simple methods, thus, avoiding or reducing the need for administering central nervous system depressants. Moreover, the use of long-lasting local anesthetics (e.g., L-bupivacaine) mixed with short acting local anesthetics (e.g., lidocaine) induce a rapid analgesic block. The use of an electrical nerve stimulator has no contraindications in the severely injured trauma patient, and permits a quick and precise localization of the nerves and pleuxus even by relatively unskilled attendants.

Using the tool facilitates the reception of data and creates a snapshot, which enables a global vision of the functioning 